\title{
Considerations on Mechanism Designs as Suitable for Cultural Heritage Evaluation
}

\author{
Marco Ceccarelli \\ LARM: laboratory of Robotics and Mechatronics, University of Cassino and South Latium, Cassino, Italy \\ Email: ceccarelli@unicas.it
}

Received September $14^{\text {th }}, 2013$; revised October $16^{\text {th }}$, 2013; accepted October $26^{\text {th }}, 2013$

\begin{abstract}
Copyright (c) 2013 Marco Ceccarelli. This is an open access article distributed under the Creative Commons Attribution License, which permits unrestricted use, distribution, and reproduction in any medium, provided the original work is properly cited. In accordance of the Creative Commons Attribution License all Copyrights (c) 2013 are reserved for SCIRP and the owner of the intellectual property Marco Ceccarelli. All Copyright $@ 2013$ are guarded by law and by SCIRP as a guardian.
\end{abstract}

Technological developments can be considered part of Cultural Heritage that deserves to be preserved for historical records and memories to a large public. Such a preservation can be also useful from technical viewpoints both to track past evolutions and to understand future trends. In this paper both designs and approaches for mechanism design are illustrated as worthy of being considered elements of Cultural Heritage with both above mentioned values mainly but not only for engineers. Examples of mechanism inventions and design algorithms both for whole machines and mechanism components are reported to show how technical achievements are and can be considered for Cultural Heritage in a broad sense and application, not only for technical use.

Keywords: History of MMS; History of Machines; Cultural Heritage; Past Mechanism Designs

\section{Introduction}

It is well understood that a memory of the past helps for a sure identity of subjects, communities, and persons. Such a good memory is today identified as Cultural Heritage mainly but not only for preservation of past developments and achievements in the broad sense of humanity experience (UNESCO, 2010).

In technical fields such an attention to memory of the past is addressed as History of Science and Technology, including History of Engineering in its specific expertise. History of MMS (in the past TMM) is the historiographical area dealing with history and evolution of MMS (Mechanism and Machine Science), and it is related to technical insights on Mechanism Science thanks to the activity of a community mainly referring to the IFToMM PC (Permanent Commission) for History of MMS (Koetsier, 2000).

Works on History of MMS with engineering viewpoints have been published in Proceedings of HMM Symposium series in the years 2000-2012, (Ceccarelli, 2000, 2004, Ceccarelli \& Yang 2008, Koetsier \& Ceccarelli, 2012) and in books of a series that has been recently started by Springer on History of MMS (available at http://www.springer.com/series/7481).

Even in the past, and since the beginning of a well-recognized discipline on TMM (Theory of Machines and Mechanisms) (now MMS) attention has been devoted to History of TMM to track and record technical past of MMS developments, like for example in (Chasles, 1837; Reuleaux, 1875; De Jonge, 1943; Dimarogonas, 1993; Ferguson, 1962; Hartenberg \& Jacques Denavit, 1956; Nolle, 1974; Roth, 2000), just to cite

\footnotetext{
"Corresponding author.
}

few significant literature sources.

Only recently History of MMS is recognized with technical contents not only for memory purposes (to give credits to inventors and scientists, and to track evolution of engineering procedures and theories), but even for orienting future developments along well-identified directions of MMS development. But this approach cannot be yet recognized as a technical Cultural Heritage of MMS achievement, since this historical awareness is still restricted to a small well identified technical community and is not available to a wide public of the society for a general understanding and appreciation.

Tangible MMS products can be recognized in machines that have been built and operated successfully, but even unsuccessfully, in the past as a contribution to the evolution of Technology and Society at local and worldwide levels. Even plans, drawings, and patents are recognized as MMS products with value of Cultural Heritage and in fact, they are often stored and used in museums and exhibitions of History of Science and Technology. Intangible MMS products can be also considered as referring to acquired knowledge that has been expressed in theories, algorithms, and reasoning for design and operation of machines. In general, those intangible MMS products are difficult to be identified and stored when they have been not reported in specific reports or books on corresponding tangible MMS products. In addition, even when reported in written documents or books those intangible MMS products are not considered worth full of consideration for Cultural Heritage since their technical contents make very often difficult the understanding and fruition from non-expert public. Thus, the true contribution remains hidden or even forgotten in old books or manuscripts in libraries and personal archives. 
This paper is an attempt to address attention both to tangible and intangible products of MMS activities, but with a novel attention referring to a technical content that can be understandable even to a large public and can be useful to current professionals. Indeed, the paper is aimed at illustrating the values of tangible and intangible MMS products with few significant examples. The analysis of tangible MMS products as whole masterpieces or mechanism components is extrapolated in a similar approach to evaluate intangible MMS products such as conceptual designs, theories, and algorithms. Summarizing, this paper is an attempt in the direction of illustrating how History of MMS in its many different aspects but with technical contents can be interpreted and made available as part of Cultural Heritage for Humanity, both for memory preservation and future use of acquired knowledge in MMS expertise.

\section{Cultural Heritage}

The concept of Cultural Heritage has been developed starting for preservation of archaeological/monumental goods of great significance for history of humanity. In the last two decades interest on problems and aspects of Cultural Heritage has been broadened to a large variety of areas, but still as concerning with memories of Human Society evolution referring to Archaeological and Architectural Goods. The goals for Cultural Heritage are recognized today both in goods as material objects, like an artistic masterpiece, an architectonic building, or a monument, and in developments of immaterial achievements, like a language or dialect, a folkloristic celebration, or human attitudes. The main aim of Cultural Heritage is the preservation of those goods and developments for the future generation both for their memory and use, in the general area of History of Humanity.

In general, Cultural Heritage is defined as the legacy of products of human ingenuity in the form of physical artifacts and intangible attributes of a group or community that are inherited from past generations, maintained in the present and bestowed for the benefit of future generations, as indicated in (UNESCO, 2010).

Physical or tangible Cultural Heritage products are understood as buildings and historic places, monuments, artifacts, etc., that are considered worthy of preservation for the future. These include objects significant to the Archaeology, Architecture, Science or Technology of a specific culture. Nature aspects are also important parts of a culture, encompassing the territory and natural environment, including what is scientifically known as biodiversity. The significance of physical artifacts can be interpreted against the backdrop of socioeconomic, political, ethnic, religious and philosophical values of a particular group of people. Of course, intangible Cultural Heritage is more difficult to preserve than physical objects.

The heritage that survives from the past is often unique and irreplaceable, which places the responsibility of preservation on the current generation. In general small objects such as artworks and other cultural masterpieces are collected in museums and art galleries for fruition to a large public.

Rules and laws have been developed in a recent past in order to clarify the values of Heritage items and to establish criteria and procedures for identifying and assigning credits of cultural products. Significant is the Convention Concerning the Protection of World Cultural and Natural Heritage that was adopted by the General Conference of UNESCO in 1972 (UNESCO,
2010). Then, many other standards and agreements have been elaborated at national and international levels, but mainly within the frames of architectonic goods.

In extending the above concepts to technical areas and particularly to engineering fields of MMS, we may consider as tangible goods the machinery and their components together with their mechanical designs still functioning or not, and we may consider as intangible goods procedures and algorithms for designing and operating those machines.

But how to identify a machine or a development in MMS as a piece of Cultural Heritage? This is usually done for traditional heritage goods by using historical studies, but considerations are also used in the frames of aesthetics, anthropology, nature preservation, and other Humanity disciplines, even by looking at economic aspects and legal constraints. Thus, from historical viewpoint it is not difficult to identify a piece worth full of memory preservation, mainly from a far past. Activities for Cultural Heritage identification can be carried out with a very complex and multidisciplinary tasks. Motivations and evaluations always come from viewpoints dealing with historical considerations such as from History of Humanity, History of Art, History of Architecture, and so on. Similarly, machines and their theoretical backgrounds can be identified as piece of Cultural Heritage by using historical studies, technical interpretations, evaluations of their impacts on the Society developments and influences on Technology, by looking yet at economic aspects and social behavior that the affected.

Preservation and fruition of goods are important aspects for Cultural Heritage value but they are also challenging activities since usually they contrast to each other. In general, goods of Cultural Heritage are stored, shown, and used in museum frames with constraints of permitting visit to a large public with just a visual inspection. In addition, more and more is requested an interaction of a visitor/user with a piece of Cultural Heritage in order to let get direct experience of significance of a piece of Cultural Heritage at large. Machine designs and their theoretical backgrounds can be stored similarly in museums and exhibitions with their tangible product counterparts but requiring specific explanations for those technical characteristics of non fairly easy understanding.

MMS developments, both as tangible and intangible products, can be studied and evaluated to create frames that can be considered for Cultural Heritage as per the significance and contribution of Technology in evolving the Humanity. This paper is aimed at proposing how History of MMS can contribute to an expansion of Cultural Heritage to technical contents by considering machines together with the corresponding engineering knowledge.

\section{Mechanism and Machine Science}

The paper is focused on potential contributions of the specific area of Mechanism Design (MD) in Cultural Heritage of technical developments. MD is a part of Mechanical Engineering (ME), since MD can include several aspects of ME as indicated in the definitions of MMS and MD as reported in IFToMM terminology. MD is linked to the broader MMS area that includes all those aspects dealing with mechanisms. In fact, MD is a specific focus on structure and functionality of mechanisms as part of machines when they are designed and operated through the outputs from all those other engineering aspects. MMS is the wide area of disciplines in mechanical engineering 
that address attention to technological developments and engineering problems that are related to mechanical systems both in their theories and applications. A clear definition of MMS is given by IFToMM, the International Federation for the Promotion of MMS (www.IFToMM.org) as (Ionescu, 2003): "Branch of science, which deals with the theory and practice of the geometry, motion, dynamics and control of: machines, mechanisms and mechanism elements and systems thereof, together with their application in industry and other contexts, in biomechanics and the environment. Related processes, such as the conversion and transfer of energy and information, also pertain to this field".

Scholars and professionals working in MMS are devoted at several levels to the many aspects that are aimed at the innovation and application of machinery in all the fields of Technology and Science. In general, machines and mechanisms are identified with their scope of transmitting or elaborating energy into motion application for the purpose of a task. Thus, interest on historical evolution of MMS can be recognized for modern developments and trends in the mechanical aspects of functioning of any system. But today for an optimized functioning other aspects than mechanical ones are also considered fundamental for machine components, such as from electric, electronic, and software fields by leading to the modern concept of Mechatronics. Thus, even disciplines from other engineering areas are now involved in MMS activities with a vision of integration of systems of different nature. Therefore, the character of science for MMS is recognized as an evolution from TMM (Theory of Machines and Mechanisms) not only for the theoretical wide backgrounds that involve even other sciences like for example Physics and Mathematics, but even for the purpose of understanding those multi-disciplinary mechatronic systems that are the today machines. Within this science view of MMS it is considered fundamental also the knowledge and understanding in historical evolutions of machines and their theoretical backgrounds.

The communities working on MMS are aggregated in societies at local, national, and international levels even with different focuses both within academic and professional frames. In particular, the MMS community can be well characterized by indicating the main international bodies that are also linked to those national and local entities. They are IFToMM and ASME, American Society of Mechanical Engineering. Within their activities, through many divisions and committees on specific technical fields, they carry out activities for advanced formation, coordination of international research activities, editorial plans, and conference organizations to facilitate the circulation of achievements and discussion of novel problems. Other forum of discussion and achievement presentation for MMS areas are the several journals that are published at national and international frames as linked to those engineering societies or international publishers.

The History of MMS is addressed with a wide activity within the above-mentioned technical frames, but with the peculiar character of being attached to engineers' interest with engineering approaches mainly for understanding and future developments of past achievements. It is worth to mention the IFToMM Permanent Commission for History of MMS and ASME Committee for History and Heritage in Mechanical Engineering. With their activity they promote a consideration of the past in MMS mainly for technical scholars and professionals. Nevertheless, efforts are attempted to direct those ac- tivities also to a large public, like for example with a IFToMM book series on history of MMS see

http://www.springer.com/series/7481) and an ASME inventory of Landmarks (ASME, 1996).

\section{History of MMS for Cultural Heritage}

In Figure 1 summary of main aspects that can contribute to an evaluation of a product in History of MMS as Cultural Heritage good is represented by stressing the multidisciplinary of such an evaluation with the above-mentioned considerations. The scheme has not the aim to be exhaustive and indeed a complementary view is needed as contributed by historians of Cultural Heritage. The concept and corresponding list of necessary steps in Figure 1 are indicated to stress that the achievements in MMS can be treated as any other products of Cultural Heritage in Technology. Thus, this overview is thought convenient to show the feasibility of such a consideration and not to propose new procedures.

Evaluation and identification of a mechanism design for Cultural Heritage with characters in Figure 1 can be outlined similarly to traditional Cultural Heritage procedures with the following steps:

- get general information, as a first screening activity of matter of interest in multidisciplinary contexts

- search for original documents and source of information, as regarding an investigation of historical sources with multidisciplinary views

- validate the documents and sources by means of a historiographical work, even with help of historians

- analyze the document for technical soundness as related to its time

- understand the technical influence and effects on technical developments of the time and subsequent periods

- consider the social impact in society developments

- evaluate other aspects for quoting the document as valuable as product of Cultural Heritage with fruition for a large public

- submit the document interpretation to the community for validating the value as product of Cultural Heritage.

The above procedure summarizes a complex activity that will require a multidisciplinary approach with cooperation of experts also in areas other than in Cultural Heritage. An existing approach can be considered that one that has brought and brings pieces of technical achievements in terms of built machines and textbooks in Science museums. But most of the time those exhibitions are aimed only at surprising visitors with past solutions, which have some modern appearance or content. Signifi-

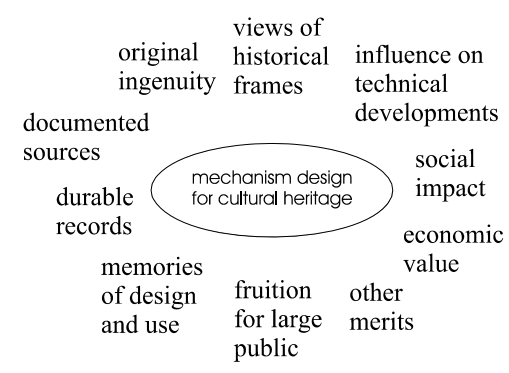

Figure 1.

Main aspects for evaluating mechanism designs as products for cultural heritage. 
cant examples with aspects for large public fruition can be indicated in the Smithsonian Museum in Washington, British Museum in London, and Science Museum in Milan. The fails of MMS exhibits in the cited museums can be understood in the fact that those exhibits show just some products but they do not give the possibility to have an overview of their MMS characters with even the corresponding theoretical backgrounds. A complete fruition of a mechanism design as product for Cultural Heritage will require a more wide understanding and explanation both in a mechanical design and theoretical aspects. Since a preliminary stage of such awareness it would be convenient to convince technical experts and historians that even mechanism designs both in constructions and procedures, are worth full to be considered as product for Cultural Heritage in a broad sense and not only as a show of the past expertise.

Attempts in direction of building collections of mechanism designs are experienced in a recent past, but mainly in the form of products (models, books, machine scaled reconstructions) for museum exhibitions or just in archives but with a limited access to a large public. Significant examples can be indicated in the mechanism collections in Bauman Technical University in Moscow (Russia), Cornell University in Cornell (USA), Dresden Technical University (Germany), and Turin Technical University (Italy), just to cite few significant ones. The cited University collections are not available to a general public and they are mainly focused on technical issues. A very recent focused plan towards Cultural Heritage of mechanism designs can be considered in the European project “Thinkmotion” (7FP EU project: CIP-ICT-PSP.2009.2.3 for years 2010-2013), whose aim is to make the History of MMS available to a large public by means of a digital library through the Europeana webpage of the European Community.

\section{A Short Outline of MMS Developments}

Over the time changes of needs and task requirements in Society and Technology have required continuous evolution of mechanisms (the term is used as mechanical system) and their uses, with or without a rational technical consciousness. In past evolution, technical knowledge has made possible to propose more and more solutions enhancing mechanisms and their uses in order to satisfy demands with updated aspects for Technology and Society.

Mechanisms and machines have addressed attention since the beginning of Engineering Technology and they have been studied and designed with successful activity and specific results. But TMM (Theory of Machines and Mechanisms) has reached a maturity as independent discipline only in the 19-th century. Today we refer to TMM as MMS because of a more wide engineering area of interest and application of mechanism concept.

The historical developments of mechanisms and machines can be divided into periods with specific technical developments that, according to author's personal opinion, can be identified and characterized by referring to significant starting events such as:

- Utensils in Prehistory;

- Antiquity: 5-th cent. B.C. (Mechanos in Greek theatre plays);

- Middle Ages: 275 (sack of the School of Alexandria and destroy of Library and Academy);

- Early design of machines: 1420 (the book Zibaldone with designs by Filippo Brunelleschi);

- Early discipline of mechanisms: 1577 (the book Mechanicorum Liber by Guidobaldo Del Monte);

- Early Kinematics of mechanisms: 1706 (the book Traitè des Roulettes by Philippe De La Hire);

- Beginning of TMM: 1794 (Foundation of Ecole Polytechnique);

- Golden Age of TMM: 1841 (the book Principles of Mechanism by Robert Willis);

- World War Period: 1917 (the book Getriebelehre by Martin Gruebler);

- Modern TMM: 1959 (the journal paper Synthesis of Mechanisms by means of a Programmable Digital Computer by Ferdinand Freudenstein and Gabor N. Sandor);

- MMS Age: 2000 (re-denomination of TMM by IFToMM);

The historical evolution to the current MMS can be shortly outlined by looking at developments that occurred since the Renaissance. Mechanisms and machines were used and designed as means to achieve and improve solutions in other fields. Specific fields of mechanisms grew in results and awareness so that first personalities were recognized as brilliant experts, like for example Francesco Di Giorgio Martini and Leonardo Da Vinci among many others, as emphasized in (Ceccarelli, 2008). At the end of Renaissance Mechanics of Machinery addressed a great attention also in Academic world, starting from the first classes given by Galileo Galilei in 1593-98 (Ceccarelli, 2006). The designer figure evolved to a professional status with strong theoretical bases finalizing a long process only in 18-th century. In Renaissance prominent was the activity of closed small communities of pupils/co-workers after “maestros" and "maestros” (Ceccarelli, 2001, 2008). Academic activity increased basic knowledge for rational design and operation of mechanisms. First mathematizations were attempted and fundamentals on mechanism kinematics were proposed by first investigators, who were specifically dedicated to mechanism issues, like for example Philippe De la Hire among many others. The successful practice of mechanisms was fundamental for relevant developments in Industrial Revolution during which many practitioners and researchers implemented the evolving theoretical knowledge in practical applications and new powered machines. The 19-th century can be considered the Golden Age of TMM since relevant novelties were proposed both in theoretical and practical fields. Mechanisms were the core of any machinery and any technological advance. A community of professionals was identified and specific academic formation was established worldwide. TMM gained an important role in the development of Technology and Society. Several personalities expressed the fecundity of the field with their activity, like for example Franz Reuleaux among many others. The first half of 20-th century saw the prominence of TMM in mechanical (industrial) engineering but with more and more integration with other technologies. A great evolution was experienced when with the advent of Electronics, it was possible to handle contemporaneously several motors in multi-d.o.f. applications of mechanisms and to operate 3D tasks with spatial mechanisms. The increase of performance (not only in terms of speed and accuracy) required more sophisticated and accurate calculations that have been possible with the advent of Informatics means (computers and programming strategies). Technically, MMS can be seen as an evolution of TMM as having a broad content and view of a Science, including new disciplines, even with multidiscipline contents. 
Systems, inventions, theories, algorithms, applications and general technical events are part of this evolution that can be considered forming Cultural Heritage of MMS developments. Those achievements have been developed by a community and in particular by individuals, whose efforts and activities are also interesting and indeed worth full of consideration for Cultural Heritage value, as pointed out with technical emphasis in the book series, and particularly in its Volumes 1 and 7, in which biographical notes are combined with memories and modern interpretation of those achievements.

\section{Examples of Theories and Algorithms}

Intangible goods for a Cultural Heritage of MMS can be considered intellectual activities and results such as for example theories, algorithms for analysis and synthesis, formulation of design criteria and performance indices, machine operation strategies, modeling of structures, kinematic concepts.

Although the above intangible products can be stored in publications that can be themselves tangible goods, those products of MMS achievements in terms of acquired knowledge require specific attention for preservation both in understanding and interpreting original value for the future, also for a suitable fruition by a large public.

In the following, few examples of those MMS heritage products are reported with a short discussion both to show samples from different historical periods and to illustrate peculiarities of their evaluations as well as their values for Cultural Heritage with the above-mentioned aspects.

In Figure 2 a page of handwritten treatise by Francesco di Giorgio in (Galluzzi, 1991) is shown as a record of an early classification of machines referring to pumping systems. Likewise the case of disk records of songs, the product itself is a piece of Cultural Heritage (as in fact it is considered as a very valuable document in a science museum). But its great value for Cultural Heritage can be better recognized in the conceptual achievement of considering different mechanical designs of machines as referring to a unique topology, even with a very early concept of kinematic inversion (as in the middle right figure) in which an inverted crank-slider mechanism can be identified. This is an example of early theoretical works that can be appreciated without formulation but with relevant MMS achievements that deserve preservation and consideration in future generations.

Figure 3 shows schemes by Guidobaldo Del Monte in his book (Del Monte, 1577) as very early kinematic models to study the motion capability of basic machines. They can be considered fundamental in tracking the historical evolution of abstraction of machine structures and operation that has a fundamental role in computational engineering both for design and operation of systems.

Another example is the notation proposed by Charles Babbage in 1826 for mechanism catalogue (Babbage, 1826). This notation was not considered efficient in his time and it was very quickly forgotten. But the attempt is well recorded and even mentioned in other proposals for a language of mechanism catalogue (Ceccarelli, 2000). This can motivate the need of preservation of its formulation and logics as an intermediary step of the evolution to a successful modelling that is used today. There are many of those classifications that are based on logics and rules that can be understood as intangible products that deserve to be preserved in their original state, although

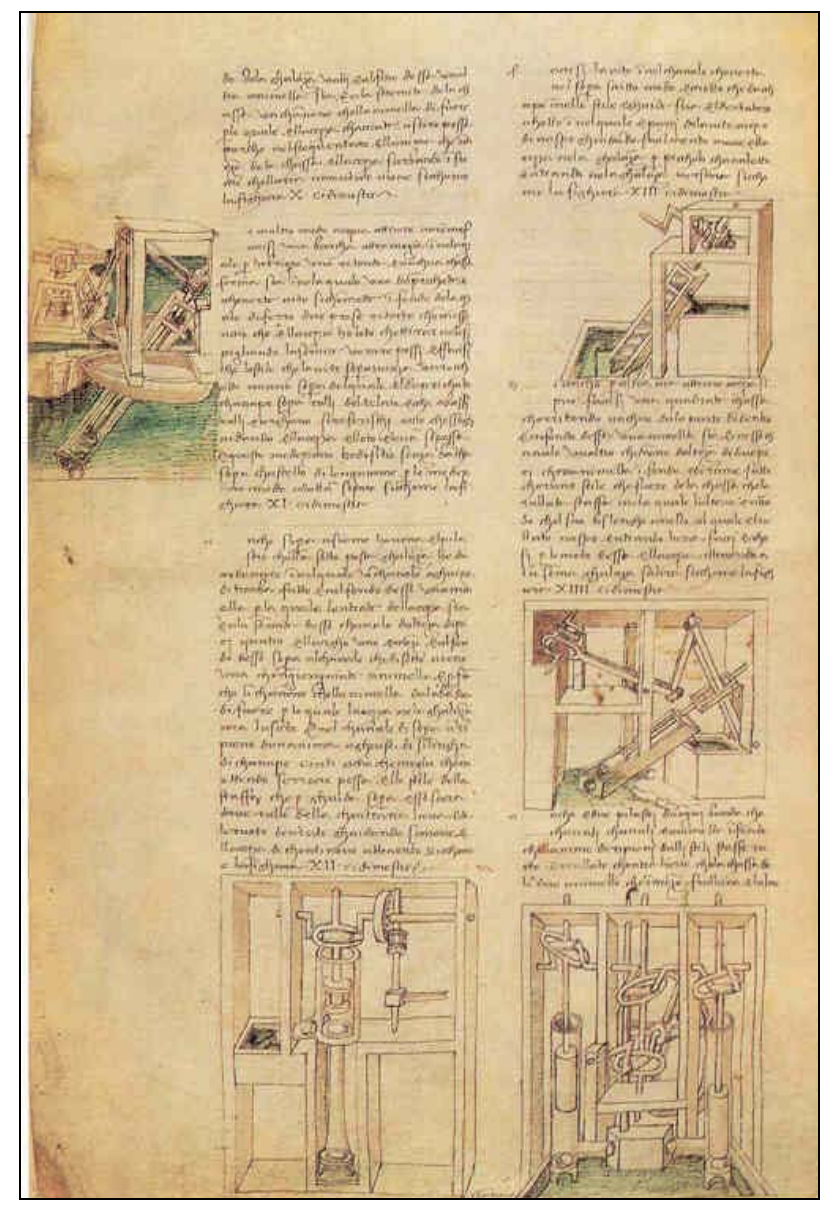

Figure 2.

Hand written manual for pumping systems by Francesco Di Giorgio (1439-1501).
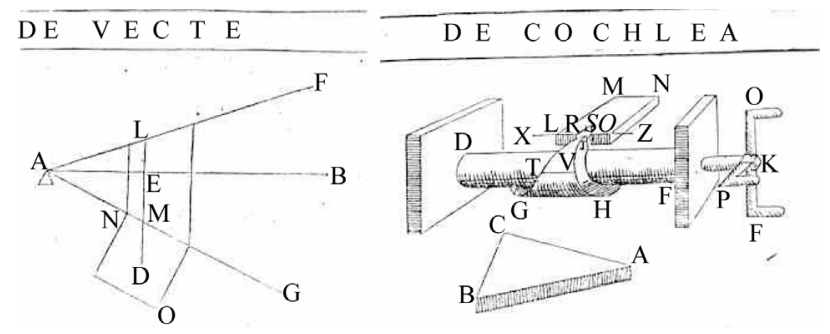

Figure 3.

Schemes of basic elementary machines/mechanisms as studied by Guidobaldo Del Monte in 1577.

nowadays they are not anymore used. This is a specific chapter of the history of MMS and its consideration will require specific attention and new evaluation as concerning a value for Cultural Heritage.

An example is illustrated in Figure 4, (Allievi, 1895), in which planar mechanisms are classified by using theoretical properties in tracing special loci in coupler curves as defined and understood by using kinematic properties and formulation. In such an evaluation significant are not only kinematic concepts but even aspects of mathematics and mechanical engineering at the same time. It is a heritage product since it is even representative of a reasoning that was under development at the 


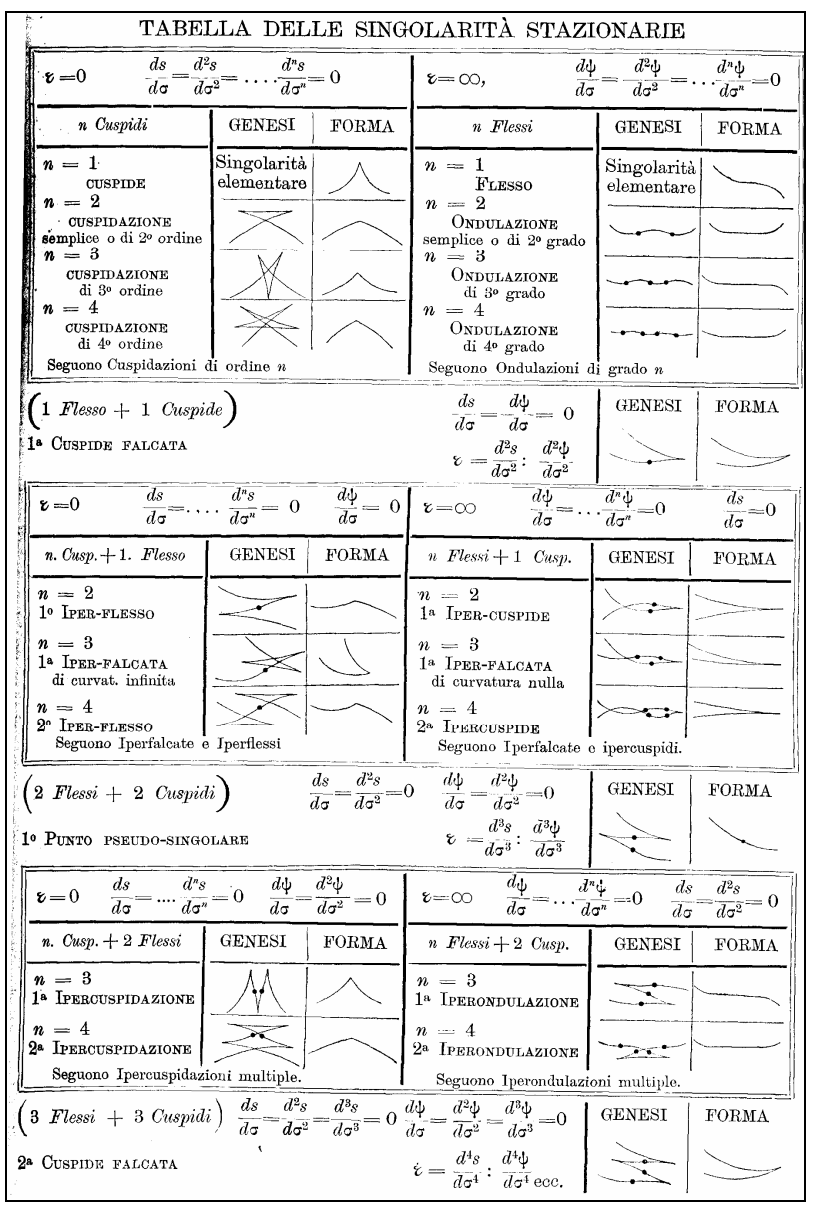

Figure 4.

A classification of coupler curves by Lorenzo Allievi published in (1895).

end of 19-th century.

Similarly, in modern time it is significant the encyclopaedic classification by Artobolevski (1975-1980), also for the social implication and general influence in more large area than only research and mechanical engineering. In this case the work can be understood as a tool for facilitating the understanding of machines and mechanisms even to a public with only basic knowledge on mechanisms since the classification is worked out with an illustration-based approach. The rich approach and the exhaustive collection can be considered itself a masterpiece for preservation of mechanisms in current practice, but in the history of mechanism design.

Figure 5 is an example that even very modern achievements of theories and algorithms can be considered suitable for preservation. This is the case of the modeling and formulation in terms of a mathematics-oriented output for development of expert systems as applied to mechanism design in (Tsai, 2001).

Other examples of theories and algorithms that deserve consideration as products for Cultural Heritage can be considered the graphical techniques that the advent of Informatics and computer calculations have made obsolete, although they are still of great interest from conceptual viewpoints. Those techniques are outlined and indeed stored in several publications during the 19-th century but a unique frame is not yet available and indeed sometimes differences are given from one author to

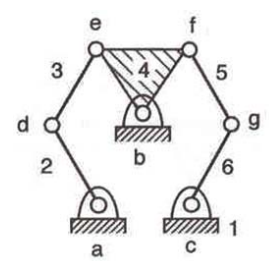

(a) Functional schematic

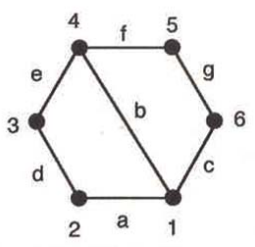

(c) Graph representation

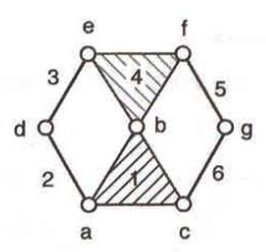

(b) Structural representation
Figure 5.

A mathematization of mechanism models by using graphs by Tsai L.W. in 2001.

another.

Other theories can be considered as those that brought to modern mathematizations and computer-oriented algorithms, whose background is often underestimated, like for example first developments of Screw Theory or algebraic approaches for mechanism analysis and synthesis. Emblematic is the case of the deduction of the sixth order formula for the coupler curve of a four-bar linkage that in modern texts is not even mentioned. Another past algorithm with modern yet interest is the analysis procedure through vector polygons, that was developed in 19-th century.

The above examples can give both samples of what could be considered intangible products of Cultural Heritage from MMS achievements but also they show the problems and peculiarities for identifying them and indeed what and how preserving their heritage values. The abstraction and even formulation behind and after acquired knowledge are what can be considered valuable aspects for Cultural Heritage. But they are complex and difficult to store with those contents of Cultural Heritage that are so far considered for the traditional heritage from mankind developments, mainly with aspects for fruition by large public that makes significant a preservation.

Main difficulty with preservation of theories and algorithms can be understood in providing suitable fruition frames for a large public so that they can fully understand and appreciate such heritage products. Up to now only expert historians with a significant technical background can fully appreciate and indeed use those past algorithms and procedures so that easily they are lost.

\section{Examples of Inventions and Mechanisms}

Similarly but with somehow more easy understanding it is possible to indicate and identify examples of tangible products of MMS that can be considered for Cultural Heritage. They are systems with their designs and operations whose remains can have a direct interpretation of historical value and significance in society developments with a fairly easy understanding.

Thus, prototypes of successful past machines, even from a recent past like those in Figure 6 can be successfully identified as goods that indicate developments of the MMS both in terms 


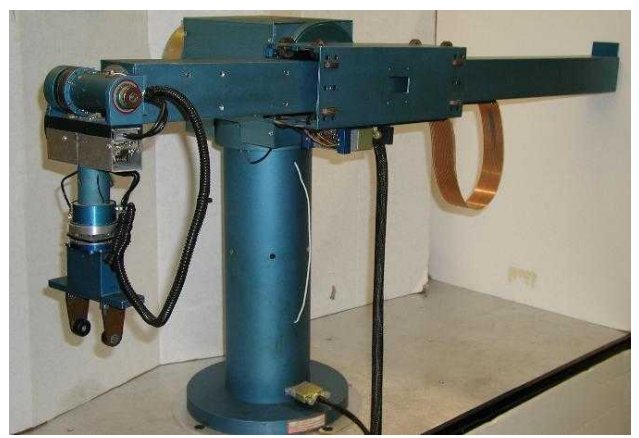

(a)

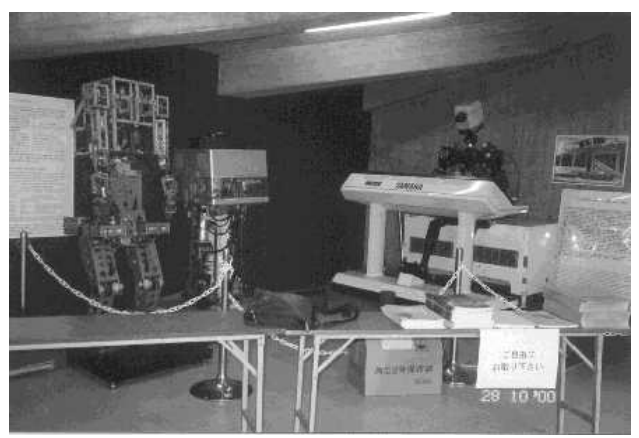

(b)

Figure 6.

Examples of system prototypes valuable as products of Cultural Heritage from robotics: (a) An early prototype of Stanford arm as stored for archiving purposes at the all of Compute Science School in Stanford University (USA); (b) Early robots from 1970' to 1980' at a show corner in Waseda University in Tokyo (Japan).

of knowledge and enhancement of quality of life. For example, the History of Robotics with a wide understanding, as indicated for example in (Ceccarelli, 2001), is full of products that have been naturally preserved by users and appreciated in general by a large public so that they are still sources of considerations for history, preservation, but also for further developments and thinking in mankind enhancements. The prototypes in Figure 6 are fundamental achievements in mechanism designs for robots and they have been preserved since the beginning of Robotics as a memory of the efforts in developing them but also to show those achievements to a large public (indeed engineering students) with a first approach of Cultural Heritage in engineering fields. Those examples are indicative that mainly in technological and engineering achievements the past is not strongly related to the time and valuable past achievements can be recognized in their historical value when they have stimulated changes and improvements in mankind developments, as today we experience with accelerated rapidity. However, the examples in Figure 6 are much more than only pieces of products, since they are the results of knowledge achievements with conceptual contents as well.

But not only big achievements with impressive shows are worth full of preservation in Cultural Heritage of MMS. In fact, even those achievements that have contributed, even considerably, but with a slow but incisive influence on the progress are worth full to be considered. Emblematic examples are the machines and mechanisms that have been developed during the Renaissance to give new impulse to society development. They are already recognized of historical value but not in a full sense of Cultural Heritage since most of the time they are preserved for showing just the past skills in engineering and technology. In Figures $\mathbf{7}$ to $\mathbf{1 1}$ examples of different machines from different periods are illustrated as from such exhibitions with no other goals. In Figure 7(a) the machine significance is even reproduced in an architectonic decoration of an important building of the time. In Figure 7(b) a wheelchair mechanism is shown as a complementary furniture of a aristocratic palace. This is a case in which a mechanism design has been fundamental for the quality of life but somehow not recognized as a technical achievements, likewise only in the last decades new medical devices are considered of priority interest since the growth of elder population.

In Figure 8 examples are shown in terms of vehicles that are stored as decoration both in technical environments of Univer-

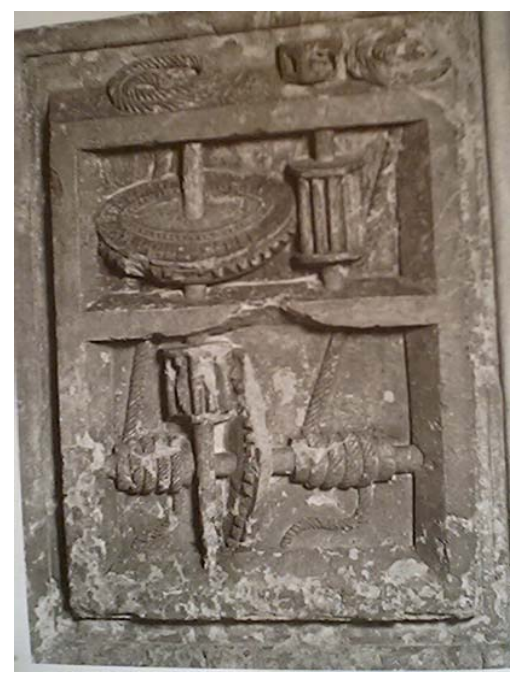

(a)

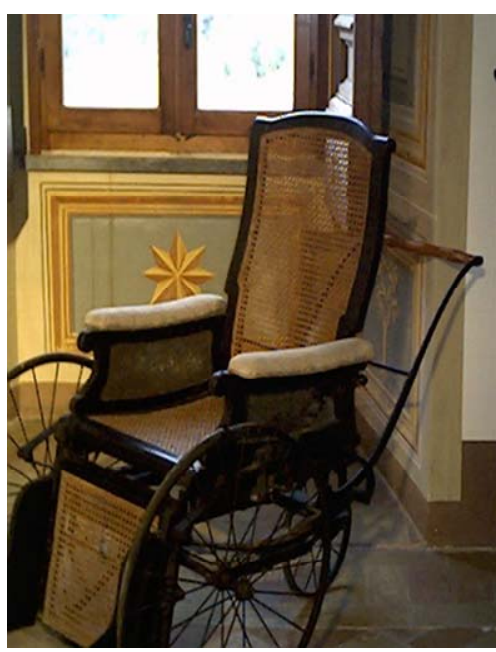

(b)

\section{Figure 7.}

Exhibitions in palace museums: (a) A 16-th cent. basso-relief as decoration of Urbino Palace celebrating machine design with gears; (b) A 19-th cent. Wheelchair with suspension mechanisms and steering back wheel at Chigi Palace in Ariccia (Rome). 


\section{CECCARELLI}

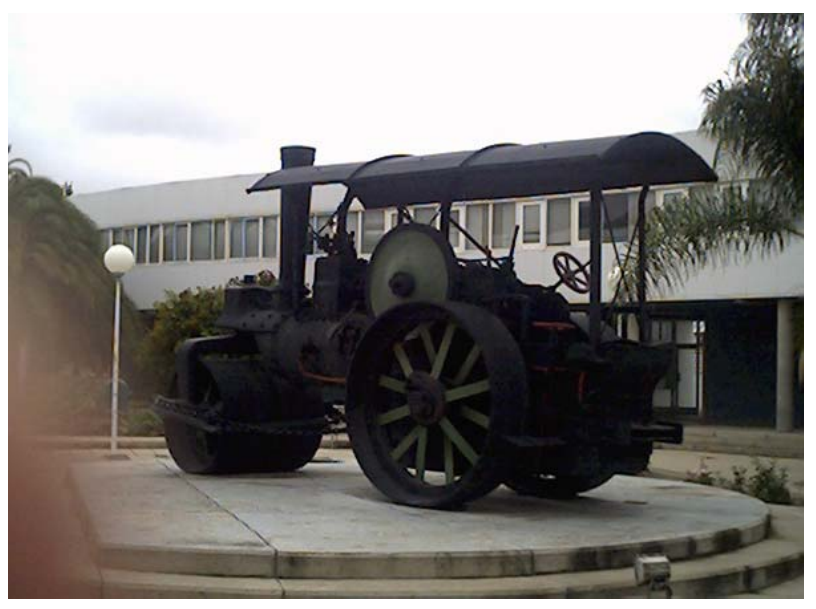

(a)

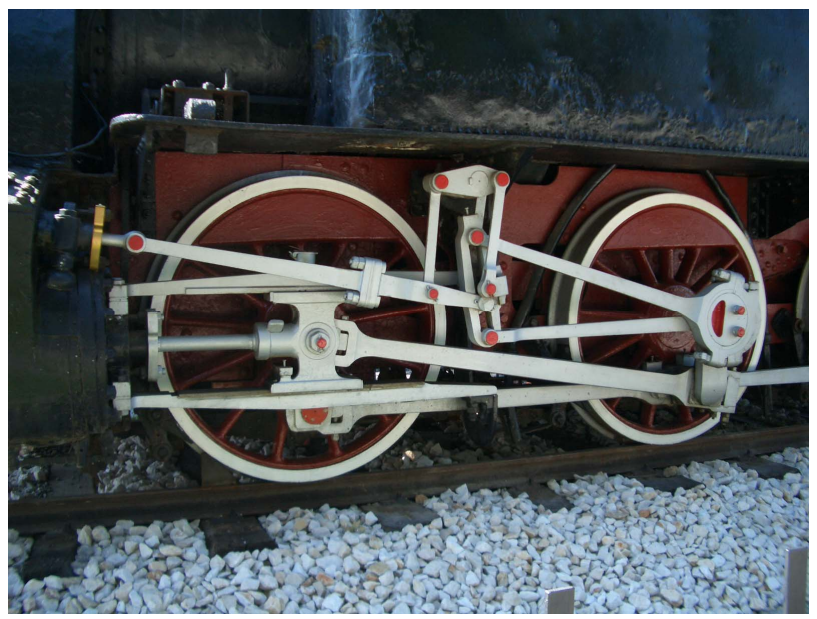

(b)

Figure 8.

Exhibition of machines of the past: (a) A steam machine for road construction in the campus of school of engineering in Las Palmas (Spain); (b) Steam powered locomotive from late 19-the century in a garden square in Brescia (Italy) with details of the force transmitting Stephenson mechanism.

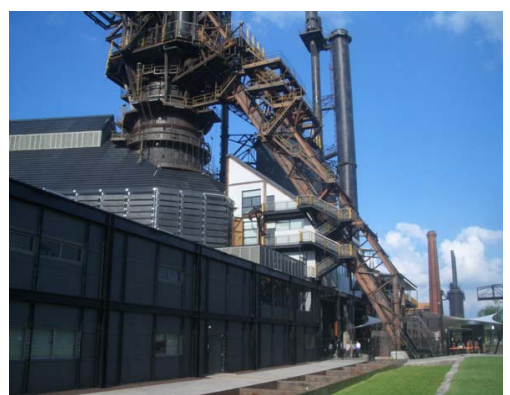

(a)

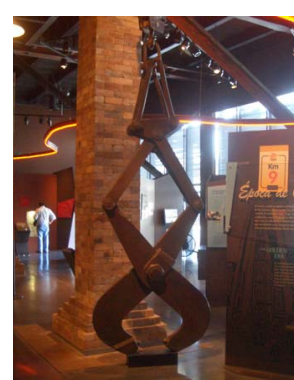

(b)
Figure 9.

A iron production plant preserved as Science Museums in Mexico: (a) overall view of the structures; (b) a show of a mechanism for a large gripper.

sities and also in city frames. Sometimes, like the case in Figure 8(b) some emphasis, even through colored repainting, is

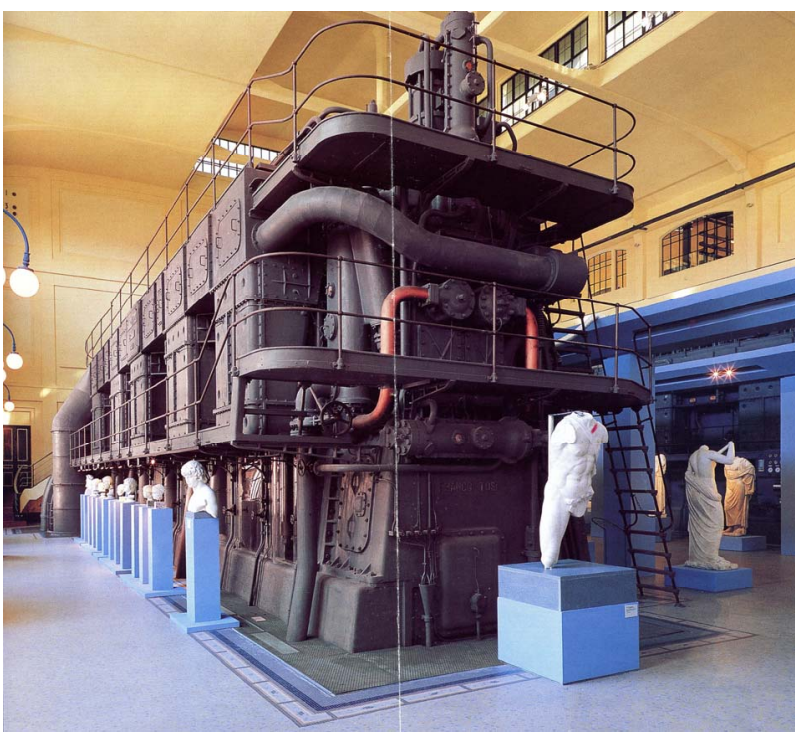

Figure 10.

A power plant of 1910's as art museum in Rome.
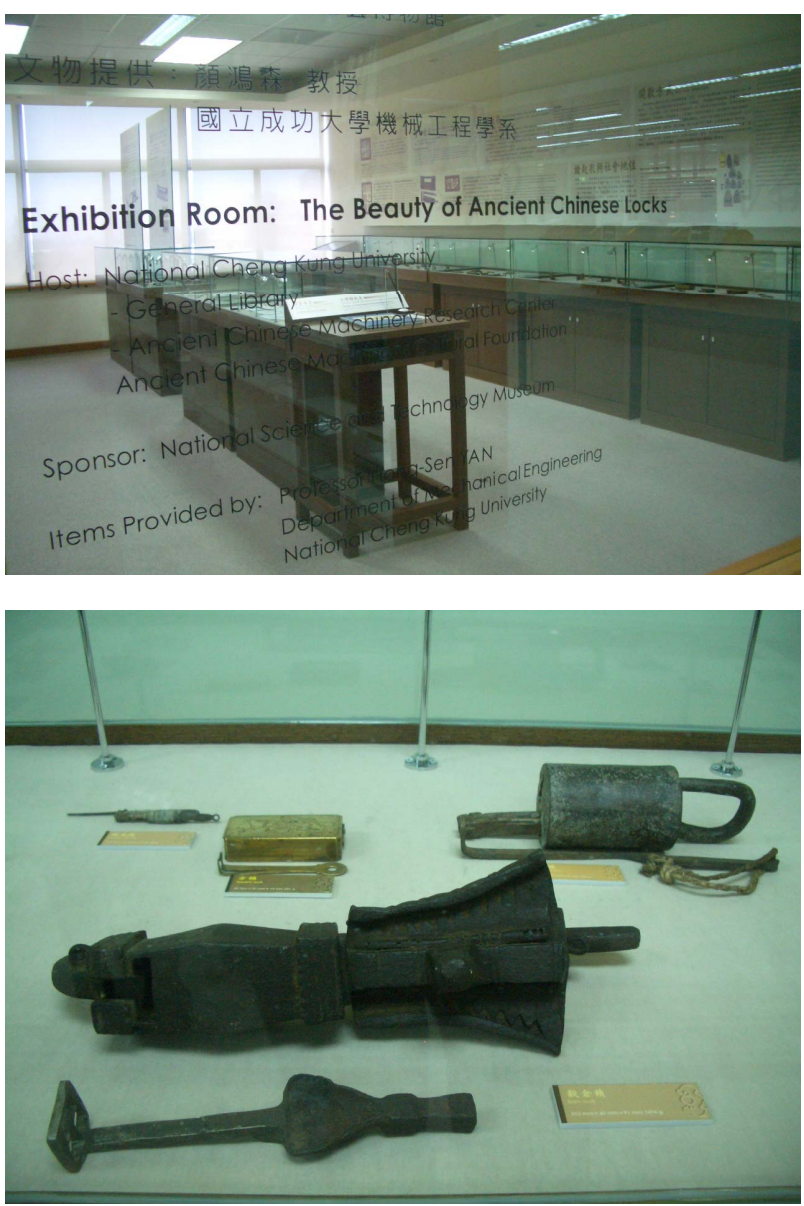

Figure 11.

An exhibition of a collection of ancient Chinese lock mechanisms at Tainan University (Taiwan).

given to the past complex mechanisms that were used in those vehicles. It is also remarkable that the size of machinery is not 
today a limitation in such a preservation, as it is the case in Figure 9 where a successful attempt of a Cultural Heritage preservation is achieved by using a large industrial plant as a museum that is dedicated to the corresponding technology in order to illustrate also the social life during its working times. The potentiality of industrial plants for Cultural Heritage sites can be also demonstrated by the cases in which they are used as museum frames not only for the specific technical areas they represent, but even as stimulating space for museum exhibition of arts, like for example the case in Rome where a plant of the 1910's with diesel engines for energy production is used to host exhibition of Roman sculptures, Figure 10.

In Figure 11 a museum room is shown as specifically dedicated to preservation of lock mechanisms within a frame illustrating historical evolution and variety of solutions. This show room is a very peculiar case since it has been established thanks to the interest and efforts of Prof. Hong-Sen Yan, but mainly as due to his curiosity and passion in those specific mechanisms of the past. Several other collections of mechanism designs exist with a similar motivation and they are indeed hidden either in University frames with reduced availability for a public fruition or in museum frames with limited estimation and explanation of influence in the cultural development of the society. An example of such university collections is illustrated in Figure 12 in which wood models of mechanisms that were used for teaching purposes, are now just stored with no possibility of understanding and fruition.

Significance of past mechanism designs is also appreciated when reconstructions are proposed in order to fully study the design and operation of the achievements. In some cases reconstructions are even shown with the aim to make understandable the functioning of the past mechanism designs to a wide public, as in the examples of Figure 13. Those reconstructions can be still considered products of Cultural Heritage since they preserve and make available past machinery that had influence in the society evolution. However, for a full heritage evaluation, preservation should include also a procedure on how they have been originally designed and even the technology and process that made possible their operation at the time of their success.

\section{Conclusion}

Cultural Heritage has the aim to identify and preserve significant achievements of humanity developments in durable
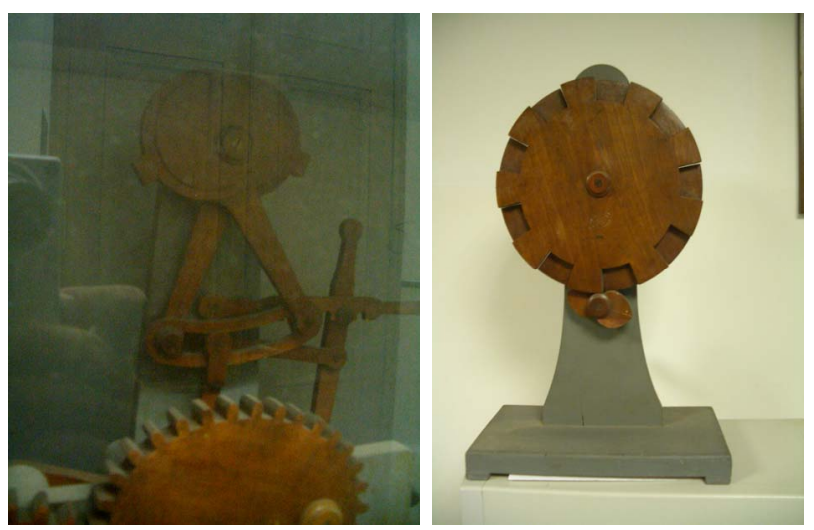

Figure 12.

Wood mechanism models from early 1950' at the school of Engineering of La Sapienza University of Rome (Italy).

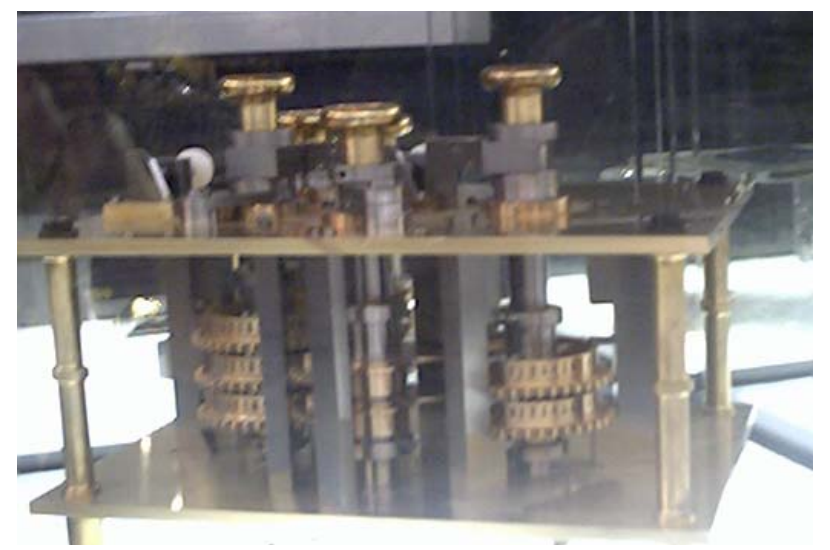

(a)

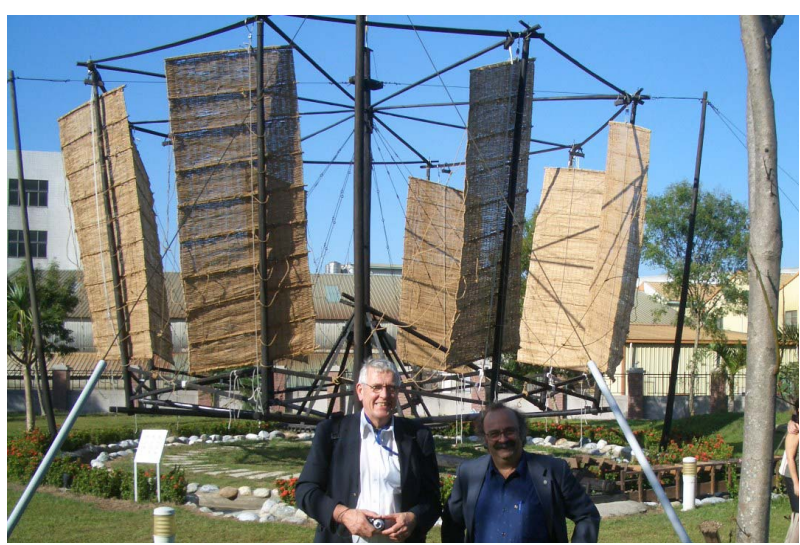

(b)

\section{Figure 13.}

A modern reconstruction of past mechanisms: (a) a module of Babbage mechanical calculator at Science museum Elder in Las Palmas (Spain); (b) a functioning reconstruction of ancient Chinese wind mill at a Taiwan University in 2008.

records and memories that can be useful to future generations, not depending on the fashion of the time. This paper is an attempt to present achievements from Mechanism and Machine Science, both in physical products and intangible knowledge, as worth fully being considered elements of Cultural Heritage for a wide public that can recognize ultimately the significance and contribution of MMS in humanity developments. The proposed examples are chosen to show both the wide range of time and place, and the variety of achievements in MMS as products of Cultural Heritage value. Each of these examples will need indeed a specific study and consequent evaluation as relevant product of Cultural Heritage. The purposes of those examples are also to show a continuity of those MMS achievements both in time and contents during the MMS history.

\section{REFERENCES}

Allievi, L. (1895). Cinematica della biella piana. Napoli: Regia Tipografia Francesco Giannini \& Figli.

Artobolevsky, I. I. (1075). Mechanisms in Modern Engineering (Vol. 5). Moscow: Mir Publisher.

ASME Int. History and Heritage (1997) Landmarks in Mechanical Engineering. West Lafayette: Purdue University Press.

Babbage, C. (1826). On a method of expressing by signs the action of machinery. Philosophical Transactions of the Royal Society, 116, 


\section{CECCARELLI}

250-265.

Ceccarelli, M. (1998). Mechanism Schemes in Teaching: A Historical Overview. ASME Journal of Mechanical Design, 120, 533-541.

Ceccarelli, M. (2000). Classifications of mechanisms over time. International Symposium on History of Machines and MechanismsProceedings of HMM. Dordrecht: Kluwer Academic Publishers, 2000): 285-302.

Ceccarelli, M. (Ed.) (2000). International Symposium on History of Machines and Mechanisms_Proceedings of HMM. Dordrecht: Kluwer Academic Publishers.

Ceccarelli, M. (2001). A Historical Perspective of Robotics toward the Future. Fuji International Journal of Robotics and Mechatronics, 13, 299-313.

Ceccarelli, M. (Ed.) (2004). International Symposium on History of Machines and Mechanisms-Proceedings of HMM. Dordrecht: Kluwer Academic Publishers.

Ceccarelli, M. (2006). Early TMM in Le Mecaniche by Galileo Galilei in 1593. IFToMM Journal Mechanism and Machine Theory, 41, 1401-1406.

Ceccarelli, M. (2008). Renaissance of Machines in Italy: From Brunelleschi to Galilei through Francesco di Giorgio and Leonardo. IFToMM Journal Mechanism and Machine Theory, 43, 1530-1452.

Ceccarelli, M., \& Yan, H.-S. (Eds.) (2008). International Symposium on History of Machines and Mechanisms-Proceedings of HMM. Dordrecht: Springer.

Del Monte, G. (1577). Mechanicorum liber. Pesaro.

Chasles, M. (1837). Apercu historique sur l'origin et le développement des méthodes en géométrie..., Mémoires couronnés par l'Académie de Bruxelles (Vol. 11, 2nd ed.). Paris.

De Jonge, A. E. R. (1943). A brief account of modern kinematics. Transactions of the American Society of Mechanical Engineer, 65, 663-683.
Dimarogonas, A. D. (1993). The origins of the theory of machines and mechanisms, modern kinematics-Developments in the last forty years. New York: Wiley, 3-18.

Ferguson, E. S. (1962). Kinematics of mechanisms from the time of Watt. Contributions from the Museum of History and Technology paper 27, Washington, 186-230.

Galluzzi, P. (Ed.) (1991). Prima di Leonardo-Cultura delle macchine a Siena nel Rinascimento. Milan: Electa.

Hartenberg, R. S., \& Denavit, J. (1956). Men and Machines... an informal history. Machine Design, 75-82,101-109,84-93.

Koetsier, T. (2000). Mechanism and machine science: Its history and its identity. International Symposium on History of Machines and Mechanisms-Proceedings of HMM. Dordrecht: Kluwer Academic Publishers, 5-24.

Koetsier, T., \& Ceccarelli, M. (Eds.) (2012). Explorations in the History of Machiens and Mechanisms-Proceedings of HMM, Dordrecht: Springer.

Ionescu, T. (Ed.) (2003). Standardization of Terminology. IFToMM Journal Mechanism and Machine Theory, 38, 7-10.

Nolle, H. (1974). Linkage coupler curve synthesis: A historical review -I and II. IFToMM Journal Mechanism and Machine Theory, 9, 147-168,325-348;

Reuleaux, F. (1875). Theoretische Kinematic-Chapter 1. Braunschweig.

Roth, B. (2000). The search for the fundamental principles of mechanism design. International Symposium on History of Machines and Mechanisms-Proceedings of HMM. Dordrecht: Kluwer Academic Publishers, 187-195.

Tsai, L.-W. (2001). Mechanism design: Enumeration of Kinematic Structures according to Function. Boca Raton: CRC Press.

UNESCO (2010). Cultural heritage. http://portal.unesco.org/culture/ 